\title{
Driving simulator performance of Veterans from the Iraq and
}

\section{Afghanistan wars}

\author{
Melissa M. Amick, PhD; ${ }^{1-2 *}$ Melissa Kraft, PsyD; ${ }^{1}$ Regina McGlinchey, PhD ${ }^{1,3}$ \\ ${ }^{1}$ Translational Research Center for TBI and Stress Disorders, Department of Veterans Affairs (VA) Boston Healthcare \\ System, Boston, MA; ${ }^{2}$ Department of Psychiatry, Boston University School of Medicine, Boston, MA; ${ }^{3}$ Geriatric \\ Research Education and Clinical Center, VA Boston Healthcare System, Boston, MA; and Department of Psychology, \\ Harvard Medical School, Boston, MA
}

\begin{abstract}
Driving simulator performance was examined in Operation Iraqi Freedom/Operation Enduring Freedom (OIF/ $\mathrm{OEF}$ ) Veterans to objectively evaluate driving abilities among this cohort who self-report poorer driving safety postdeployment. OIF/OEF Veterans $(n=25)$ and age- and educationmatched civilian controls $(n=25)$ participated in a 30 min driving simulator assessment that measured the frequency of minor, moderate, and severe driving errors. Frequency of errors in specific content domains (speed regulation, positioning, and signaling) was also calculated. All participants answered questions about number of lifetime traffic "warnings," moving violation tickets, and accidents. Veterans completed the Posttraumatic Stress Disorder (PTSD) Checklist-Military Version. On the driving simulator assessment, Veterans committed more minor, moderate, severe, and speeding errors and reported poorer lifetime driving records than the civilian control group. Exploratory analyses revealed an association between increasing errors on the driving simulator with increasing symptoms of PTSD, although statistically this correlation did not reach significance. These findings suggest that Veterans perform more poorly on an objective evaluation of driving safety and that the presence of PTSD could be associated with worse performance on this standardized driving simulator assessment.
\end{abstract}

Key words: accident, activity of daily living, deployment, military, motor vehicle, OIF/OEF, posttraumatic stress disorder, reintegration, safety, virtual reality.

\section{INTRODUCTION}

Motor vehicle crashes (MVCs) are among the leading causes of injury-related disability, hospitalization, and outpatient visits across the military [1] and are the most common cause of death among U.S. Army servicemembers in the early years postdeployment [2]. Being deployed may increase risk for MVC-related fatalities because deployed gulf war Veterans were found to have an annual rate of 23.6 fatalities per 100,000 persons compared with nondeployed Veterans (15.9/100,000 [3]) and the general U.S. population around that time (16.3/100,000 [4]). Further underscoring the negative effect of deployment on driving safety, Operation Iraqi Freedom/Operation Enduring Freedom

Abbreviations: MANOVA = multivariate analysis of variance, MVC $=$ motor vehicle crash, OIF/OEF $=$ Operation Iraqi Freedom/Operation Enduring Freedom, PCL-M = Posttraumatic Stress Disorder Checklist-Military Version, PTSD $=$ posttraumatic stress disorder, TBI = traumatic brain injury, VA = Department of Veterans Affairs.

*Address all correspondence to Melissa M. Amick, PhD; Translational Research Center for TBI and Stress Disorders, VA Boston Healthcare System (182-JP), 150 S. Huntington Ave, Boston, MA 02130; 857-364-2135; fax: 857364-4454. Email: Melissa.Amick@va.gov http://dx.doi.org/10.1682/JRRD.2012.06.0108 
(OIF/OEF) Veterans have higher rates of accidents postdeployment. Comparing the driving records for Veterans 6 mo pre- and postdeployment, it was found that at-fault accidents increased by 13 percent postdeployment [5]. Additionally, self-report measures reveal that dangerous driving [6], speeding or not wearing a seat belt [7], and anger or impatience [8-9] are commonly reported by OIF/ OEF Veterans, with one study citing upward of 80 percent of respondents reporting a global decline in driving safety postdeployment [10]. These behaviors might have been fostered during deployment because of the need to learn "battlemind" driving maneuvers. OIF/OEF servicemembers are taught life-saving evasive driving maneuvers that include speeding, swerving around objects in the road (i.e., possible improvised explosive devices), and ignoring traffic signals and signs (to avoid attack). These military driving habits may be difficult to unlearn postdeployment. Taken all together, these findings indicate that the OIF/ OEF cohort, compared with Veterans from earlier wars, could be at even greater risk for MVC injury and fatality because of the experience of deployment, self-reporting high rates of unsafe driving practices postdeployment and the unique driving practices acquired during OIF/OEF.

Posttraumatic stress disorder (PTSD) may further increase the risk of problematic driving among OIF/OEF Veterans [6-7]. Driving skills have yet to be objectively measured in persons with PTSD, even though the symptoms that comprise the hyperarousal cluster of PTSD, including anger, sleep disturbance, and concentration and/or arousal dysregulation, are among the most common risk factors for MVC fatalities among civilians [1012]. In one study, $>80$ percent of OIF/OEF Veterans with a diagnosis of PTSD reported worsening of at least one unsafe driving behavior since deployment [9]. Considering that current prevalence estimates of PTSD for OIF/ OEF Veterans have ranged between 11 and 18 percent [13-15] and future projections are upward of 35 percent [16], unsafe driving habits in this cohort may become endemic.

Self-reported aggressive driving habits, such as verbal outbursts, angry hand gestures, tailgating, cutting off or chasing other drivers, and driving under the influence of substances, have been reported by 20 to 63 percent of OIF/ OEF Veterans with PTSD, and aggressive driving habits were more prevalent in this group than in Vietnam war Veterans with PTSD [8]. Similarly, a survey of OIF/OEF Veterans from a traumatic brain injury (TBI) clinic found that $>80$ percent of participants with a PTSD diagnosis reported greater problems postdeployment with anger and impatience while driving [9]. These preliminary findings suggest that the presence of deployment-related PTSD may be another significant risk factor for unsafe driving among OIF/OEF Veterans.

MVC-related injuries, which can require lifelong medical management, are among the leading reasons for outpatient visits among military personnel [17]. While unsafe driving habits of OIF/OEF Veterans are a significant concern for the Department of Veterans Affairs (VA) and Department of Defense [18], the identification and treatment of unsafe driving practices have been underexamined among this cohort. Critically, there are very few reports on the driving safety practices of OIF/OEF Veterans, and the recent studies in this cohort are all limited by reliance on self-report measures.

Based on the previous findings of unsafe driving practices in Veterans of earlier wars, as well as selfreported increased rates of unsafe driving among OIF/ OEF Veterans, we hypothesized that an OIF/OEF Veteran sample would demonstrate poorer performance on a standardized driving simulator assessment than a civilian control group. Considering the emerging findings suggesting that PTSD is a determinant of unsafe driving among OIF/OEF Veterans, we also hypothesized that increasing symptoms of PTSD would be associated with a greater number of errors on the driving simulator in an exploratory analysis.

\section{METHODS}

\section{Participants}

Participants in this study included 25 previously deployed OIF/OEF Veterans (24 male, 1 female) and 25 civilians (16 male, 9 female). We matched Veteran and civilian participants for age and education (each within $4 \mathrm{yr}$ ). We recruited participants through institutional review board-approved informational flyers and referrals from other research studies.

We included control participants in this study if they reported no significant psychiatric history. We excluded all potential participants who had a history of a moderate TBI prior to military service, demonstrated severe cognitive impairments due to another medical condition, or had physical limitations, all of which could interfere with operating the driving simulator. 


\section{Procedures}

Study participation consisted of a single $\sim 3$ h session with a standardized order of test administration. A doctorallevel psychologist administered the protocol of self-report measures, cognitive assessment, and driving simulator evaluation.

\section{Assessments}

Posttraumatic Stress Disorder Checklist-Military Version

The PTSD Checklist-Military Version (PCL-M) is a 17-item self-report measure of PTSD symptoms experienced by Veterans who have been exposed to a militaryrelated trauma. Given that it was created to evaluate military-related traumas, the civilian control participants did not complete this measure.

\section{Driving History Questionnaire}

We asked participants to complete a questionnaire about their driving history. Participants answered the following questions:

1. How old were you when you first started to drive?

2. How many miles per week do you drive (on average for past $6 \mathrm{mo})$ ?

3. How many traffic warnings have you received (i.e., pulled over by a police officer but not issued a ticket) in your lifetime?

4. How many tickets have you received in your lifetime?

5. How many driving accidents have you experienced in your lifetime?

6. How many at-fault driving accidents have you experienced in your lifetime?

\section{Simulator Assessment}

All participants also underwent an evaluation using the Virtual $\mathrm{Rx}^{\circledR}$ Driver NDX System (Raydon; Port Orange, Florida). The simulator uses a three-monitor setup, steering wheel, gas and brake pedals, and gearshift to provide a realistic driving environment. During the simulated assessment drive, participants encounter highway, urban, and residential driving environments. Driving route directions are presented through a digital recording to guide the participant through the predetermined route. The assessment drive evaluates turning ability, merging, speed, and adherence to stop signs and traffic lights. Naturalistic obstacles are programmed into the assessment to evaluate participants' ability to avoid collisions with pedestrians, vehicles, traffic jams, parked cars, and emergency vehicles.

The driving simulator software identifies a variety of driving errors (Table 1) throughout the assessment. The Virtual $\mathrm{Rx}^{\circledR}$ Driver NDX System can capture up to three co-occurring errors. Its algorithms for error detection have been programmed so that once an error has been identified it is not counted again, even though it may last for seconds. We classified errors according to both severity and content domain (speed regulation, positioning, and signaling). For severity, we categorized errors as minor, moderate, or severe (Table 1). This resulted in four outcome measures: total errors, total minor errors, total moderate errors, and total severe errors. For content domain, we provided six doctoral-level psychologists (experimental and clinical psychologists) with a list and a description of each error recorded by the driving simulator. Each psychologist then assigned each error to a predetermined content domain. This resulted in three main content areas: speeding, positioning, and signaling. In cases where there was not full agreement, we used the most common categorization to classify the error (Table 1).

\section{Statistical Analysis}

We compared group differences on continuous measures with independent samples $t$-tests or multivariate analysis of variance (MANOVA) in cases where the dependent measures are intercorrelated. We employed Pearson $r$ statistics for correlations involving the full sample, whereas we employed Spearman $\rho$ when examining correlations within the subsample of Veteran data. We calculated differences in frequency distribution using the chi-square statistic.

\section{RESULTS}

\section{Sample Characteristics}

The Veteran group was comparable in age (control: $32.3 \pm 7.4 \mathrm{yr}$; Veteran: $33.2 \pm 7.6 \mathrm{yr}$ ) and education (control: $14.6 \pm 3.1 \mathrm{yr}$; Veteran: $13.7 \pm 2.3 \mathrm{yr}$ ) to the civilian control group. Values are mean \pm standard deviation. There were significantly fewer women in the Veteran group than the civilian control group (chi square $=8.0$, $p<0.01$ ). Performance was collapsed across sex within the civilian control group because there was no difference between male and female civilian control participants with respect to participant characteristics, driving history, or errors on the driving simulator (all $p>0.3$ ). 
JRRD, Volume 50, Number 4, 2013

Table 1.

Error classification for driving simulator.

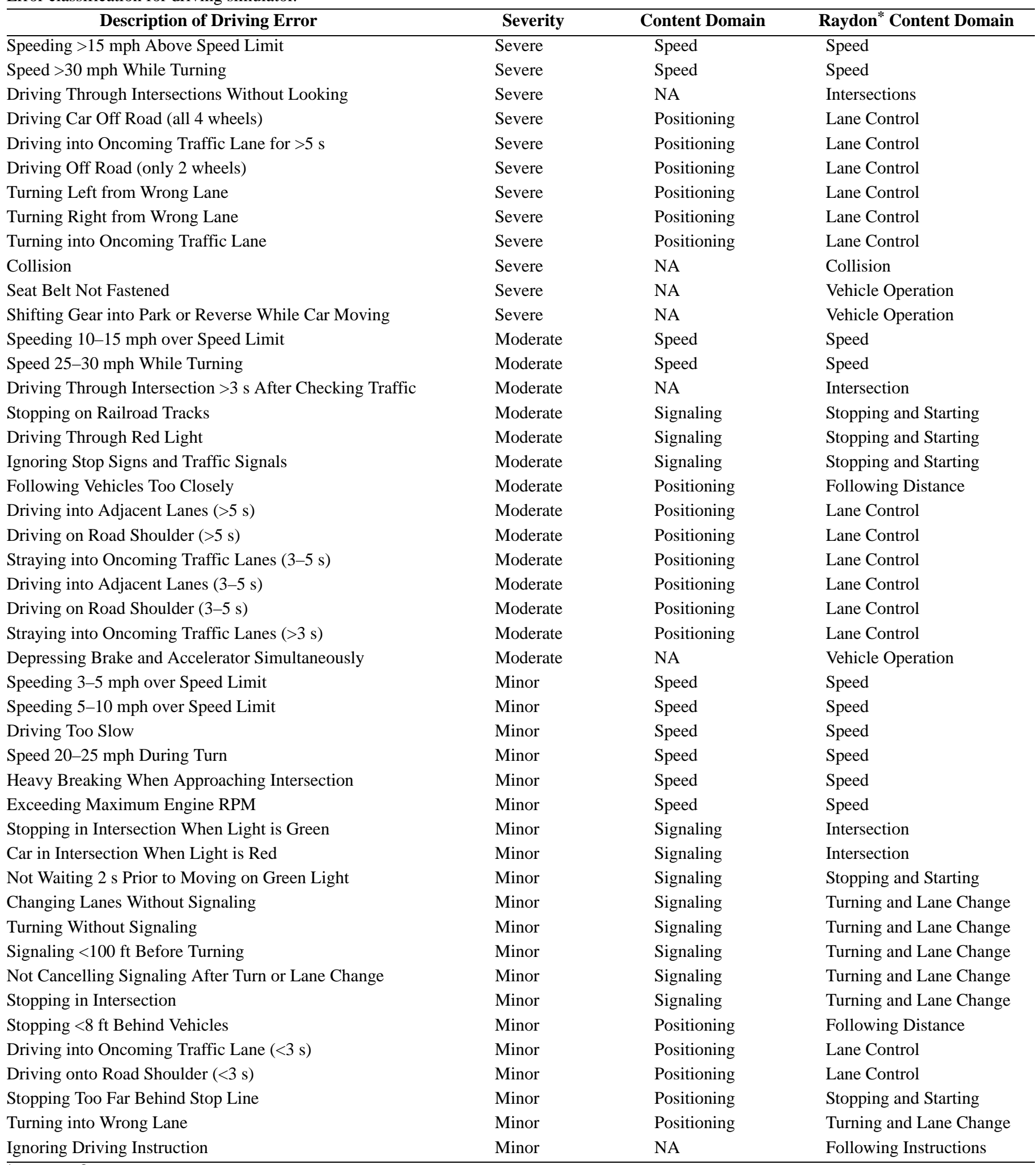

${ }^{*}$ Virtual Rx ${ }^{\circledR}$ Driver NDX System (Raydon; Port Orange, Florida). NA = not applicable, RPM = revolutions per minute. 
Driving experience and/or exposure was equivalent between the Veteran and civilian control participants because there were no significant differences between the groups in terms of age first learned to drive or number of miles driven per week (Table 2). Compared with the civilian control group, the Veteran group reported significantly more traffic warnings, moving violation tickets, and lifetime accidents but not at-fault accidents (Table 2).

\section{Driving Simulator Assessment}

\section{Driving Performance Among OIF/OEF Veterans}

The Veteran group demonstrated significantly more total errors on the driving simulator than the civilian control group $\left(F(1,48)=8.20, p<0.006, \eta^{2}=0.15\right)$ (Table 2). To examine whether groups specifically differed in the severity of errors committed on the driving simulator assessment, we conducted a MANOVA. We observed a main effect of group $\left(F(3,46)=2.98, p=0.04, \eta^{2}=0.16\right)$. The Veteran group committed more frequent severe $\left(F(1,48)=8.00, p<0.01, \eta^{2}=0.14\right)$, moderate $(F(1,48)=$ 6.87, $\left.p=0.01, \eta^{2}=0.13\right)$, and minor $(F(1,48)=4.61, p=$ $0.04, \eta^{2}=0.09$ ) errors on the simulator assessment than the civilian control group (Table 2).

We created a composite score by summing all errors associated with each of the content domains. MANOVA revealed a significant main effect of group on errors $\left(F(3,46)=3.87, p=0.02, \eta^{2}=0.20\right)$. Examining errors in specific content domains revealed that the OIF/OEF Vet- eran group demonstrated significantly more speeding errors than the civilian control group $(F(1,46)=11.51, p<$ $\left.0.01, \eta^{2}=0.19\right)$. There were no differences in the frequency of positioning $\left(F(1,46)=0.22, p=0.64, \eta^{2}=\right.$ $0.005)$ or signaling $\left(F(1,46)=0.41, p=0.52, \eta^{2}=0.009\right)$ errors between groups. The pattern of observed findings did not differ when the content domain error score was weighted for severity ([total severe errors $\times 3]+[$ total moderate errors $\times 2$ ] + [total minor errors $]$ ).

Interestingly, collapsed across groups, we observed significant correlations between the frequency of errors on the driving simulator and lifetime traffic warnings $(r(50)=0.35, p=0.01)$ as well as lifetime tickets $(r(50)=$ $0.43, p<0.002)$.

\section{Exploratory Analysis: Effect of Posttraumatic Stress Disorder}

The association between the PCL-M score and total errors approached but was not significant (Spearman $\rho=$ $0.39, p=0.06$ ).

\section{DISCUSSION}

\section{Deployment and Driving Simulator Assessment Performance}

Our findings show that Veterans performed more poorly on a standardized and objective measure of driving ability than a civilian control group closely matched for

Table 2.

Participant driving history and performance.

\begin{tabular}{lccc}
\hline Driving Characteristics & Civilian Control Group ${ }^{*}(\boldsymbol{n}=\mathbf{2 5})$ & OIF/OEF Veterans* $(\boldsymbol{n}=\mathbf{2 5})$ & $\boldsymbol{p}$-Value \\
\hline Age Learned To Drive (yr) & $16.7 \pm 2.3$ & $16.1 \pm 2.2$ & NS \\
Miles Driven per Week & $204.8 \pm 251.5$ & $147.2 \pm 168.0$ & NS \\
Simulator Minor Errors & $49.2 \pm 13.5$ & $59.4 \pm 19.3$ & 0.04 \\
Simulator Moderate Errors & $14.2 \pm 6.7$ & $23.4 \pm 16.3$ & 0.01 \\
Simulator Severe Errors & $16.3 \pm 6.1$ & $23.8 \pm 11.7$ & 0.01 \\
Total Simulator Errors & $79.7 \pm 20.4$ & $106.5 \pm 42.2$ & 0.01 \\
Total Speeding Errors & $14.8 \pm 11.8$ & $35.3 \pm 27.8$ & 0.01 \\
Total Positioning Errors & $30.2 \pm 12.2$ & $32.3 \pm 18.4$ & NS \\
Total Signaling Errors & $14.5 \pm 4.4$ & $15.4 \pm 5.6$ & NS \\
Lifetime Traffic Warnings & $2.6 \pm 2.9$ & $5.6 \pm 6.1$ & 0.03 \\
Lifetime Tickets & $1.8 \pm 1.9$ & $6.8 \pm 9.5$ & 0.02 \\
Lifetime Accidents & $1.2 \pm 1.4$ & $2.6 \pm 2.3$ & 0.02 \\
Lifetime At-Fault Accidents & $0.7 \pm 1.1$ & $1.0 \pm 1.0$ & NS \\
\hline
\end{tabular}

*Mean \pm standard deviation.

NS = nonsignificant, OIF/OEF = Operation Iraqi Freedom/Operation Enduring Freedom. 
age and education. We found group differences for errors of all severities. Group differences are unlikely to be due to driving experience because both groups reported comparable miles driven per week as well as years of driving experience. In addition, the Veteran group reported more lifetime traffic warnings, moving violation tickets, and accidents, which may suggest that simulator performance can be indicative of real-world driving infractions. In fact, collapsed across groups, we observed significant correlations between the frequency of errors on the driving simulator, lifetime traffic warnings, and tickets, which provides preliminary validation for the simulator assessment. However, information regarding when (pre- or postdeployment) the warnings and tickets occurred was not available, which limits our ability to conclude that these deficits are due to deployment. Nevertheless, supporting the notion that deployment may contribute to these unsafe driving outcomes, Veterans self-reported poorer driving habits postdeployment [10]. These data provide objective support for previous studies, which have found OIF/OEF Veterans to frequently self-report postdeployment driving difficulties.

The Veteran group also made more total speeding errors on the simulator than the civilian control group. These findings may be consistent with the self-reported greater frequency of lifetime warnings and tickets reported by the Veteran group than the civilian control group. We are limited in this conclusion, however, because we did not have our participants clarify whether these tickets were due to speeding or other types of traffic infractions. Our finding of elevated speeding errors in the Veteran group is, however, very concerning given that in the general population speeding is among the top three causes of death in MVCs [19].

\section{Posttraumatic Stress Disorder and Driving Simulator Assessment Performance}

Preliminary analyses also suggest that increasing symptoms of PTSD were associated with a greater number of total errors committed on the driving simulator, although this correlation was not statistically significant. Given that the hyperarousal cluster of PTSD, including anger, sleep disturbance, and concentration and/or arousal dysregulation, is one of the most common risk factors for MVC fatalities among civilians, the effect of certain types of PTSD symptoms on driving safety will need to be examined. Distinct from the symptoms of PTSD, pharmacological interventions for PTSD could also affect driving performance, and the relative contribution of medications on driving performance will need to be monitored in future studies. It is acknowledged that PTSD was crudely evaluated using a brief self-report symptom checklist. Future studies employing the clinician-administered assessment of PTSD will be critical to determine how the diagnosis of PTSD influences driving simulator performance in OIF/OEF Veterans.

\section{Limitations}

Several clinical conditions such as sleep disturbance, chronic pain, and substance abuse might have affected performance on the driving simulator but were not controlled for in this preliminary study. Future studies will need to examine the effect of these relatively common and often comorbid conditions (among Veterans) on driving safety. It should be acknowledged that time since deployment may be another factor that determines driving safety practices. In this study, we did not measure time since return from deployment; however, our clinical experience as well as self-report from Veterans [9] suggests that unsafe driving practices may decrease as time since deployment increases. This will be a critical factor to examine because time since deployment could be one method of identifying at-risk Veteran drivers who would benefit from driver retraining prior to any negative driving consequences. Future studies that validate our driving simulator assessment with actual on-the-road driving performance will be conducted to bolster our contention of the utility of employing driving simulators to assess Veteran driving performance.

\section{Future Directions}

Objective measurement of driving safety has mainly been assessed through on-the-road driving assessments (akin to the state driver's licensing examination) or through standardized driving simulator assessments. Driving simulation may be the preferred method of screening driving safety for OIF/OEF Veterans who appear to be more aggressive and risky drivers than the general population. Driving simulators remove the possibility of significant risk posed by actual on-the-road-assessment. Furthermore, driving simulation allows for the assessment of an individual's performance during challenging driving scenarios (e.g., crash avoidance), which would be both unfeasible and unethical to assess during an actual road test. Although the VA has a well-established on-the-road driving assessment program, driving simulation maybe a proactive method of screening potentially at-risk Veterans to identify those who 
require the more costly and time consuming on-the-road assessment services provided by the VA. Additionally, driving simulation may be a useful intervention for Veterans in order to practice driving skills under challenging conditions.

Disability from MVC is a devastating functional outcome for servicemembers, and the potential cost of managing these lifelong injuries and disabilities mandates the development of assessment tools, like our driving simulator assessment, to detect unsafe Veteran drivers. It is equally important to consider that loss of driving privileges has a devastating effect on a Veteran's functional independence, including difficulty engaging in employment, attending healthcare visits, and other community reintegration activities. For these reasons, it is critical to develop accurate screening, assessment, and interventions for unsafe driving habits. This study is the first step toward achieving these objectives. The identification of types of driving impairments demonstrated by our Veterans as well as clinical characteristics such as psychological diagnoses (e.g., PTSD, substance abuse or dependence, chronic pain) and personality traits (i.e., risk taking) that affect driving safety will be used to inform the development of a formalized screening and assessment procedure to identify individuals at risk for unsafe driving. This information can also be used to develop preventive educational interventions and specific strategies to remediate unsafe driving behaviors and prevent future accidents.

\section{CONCLUSIONS}

Our findings show that OIF/OEF Veterans, compared with a civilian control group, performed more poorly on a laboratory-based assessment of driving ability, which is associated with real-world instances of unsafe driving behaviors. In particular, Veterans distinguished themselves from the civilian control group by committing more speeding errors. This is a particularly concerning finding because speeding is a common cause of MVC fatality. Furthermore, preliminary analyses, while nonsignificant, showed that increasing symptoms of PTSD are accompanied by increasing errors on the driving simulator. These findings provide objective evidence of the significant and serious driving difficulties experienced by OIF/OEF Veterans. Given the emerging findings of pervasive unsafe driving practices reported by a large proportion of this Veteran cohort, future studies to develop assessments for the rapid identification of unsafe drivers, as well as rehabilitative interventions to improve driving safety, are needed.

\section{ACKNOWLEDGMENTS}

\section{Author Contributions:}

Study concept and design: M. Kraft, M. M. Amick.

Data collection and abstraction: M. Kraft, M. M. Amick.

Data interpretation: M. M. Amick, M. Kraft, R. McGlinchey.

Data analysis: R. McGlinchey.

Drafting of manuscript: M. M. Amick.

Revision of manuscript for important intellectual content: M. M. Amick, M. Kraft, R. McGlinchey.

Financial Disclosures: The authors have declared that no competing interests exist.

Funding/Support: This material was based on work supported by VA Merit Review (grant B5009R).

Additional Contributions: We would like to thank Terri Pogoda, $\mathrm{PhD}$, for her thoughtful contributions to the conceptualization of the driving assessments; Lisa Hankee, $\mathrm{PhD}$, for her assistance with participant recruitment and data collection; Colleen Barber, MS, for her careful editing of the manuscript; and Pat Woods, RN, for her assistance with the regulatory aspects of the study. Finally, we wish to acknowledge our appreciation to all of the participants who volunteered their time to contribute to this study. Dr. Kraft is now with the Department of Physical Medicine and Rehabilitation, Manchester VA Medical Center, Manchester, New Hampshire.

Institutional Review: This study was approved by the committee for Human Subjects Research (Institutional Review Board) at the VA Boston Healthcare System. All participants completed the informed consent process and signed the informed consent prior to their participation in the study.

Participant Follow-up: We do not plan to inform participants of the publication of this study.

\section{REFERENCES}

1. Jones BH, Amoroso PJ, Canham ML, Schmitt JB, Weyandt MB. Chapter 9. Conclusions and recommendations of the DoD Injury Surveillance and Prevention Work Group. Mil Med. 1999;164(8 Suppl):1-26. [PMID:10847817]

2. Krull AR, Jones BH, Dellinger AM, Yore MM, Amoroso PJ. Motor vehicle fatalities among men in the U.S. Army from 1980 to 1997. Mil Med. 2004;169(11):926-31. [PMID:15605944]

3. Lincoln AE, Hooper TI, Kang HK, Debakey SF, Cowan DN, Gackstetter GD. Motor vehicle fatalities among Gulf War era veterans: characteristics, mechanisms, and circumstances. Traffic Inj Prev. 2006;7(1):31-37. [PMID:16484030] http://dx.doi.org/10.1080/15389580500412028 
4. Sivak M. Motor-vehicle safety in Europe and the USA: A public-health perspective. J Safety Res. 1996;27(4):225-31. http://dx.doi.org/10.1016/S0022-4375(96)00027-8

5. USAA. Returning warriors: Driving safety report 2012 [Internet]. San Antonio (TX): USAA; [2012]. Available from: https://content.usaa.com/mcontent/static assets/Media/ Returning_Warriors_report_summary.pdf

6. Sayer NA, Noorbaloochi S, Frazier P, Carlson K, Gravely A, Murdoch M. Reintegration problems and treatment interests among Iraq and Afghanistan combat veterans receiving VA medical care. Psychiatr Serv. 2010;61(6): 589-97. [PMID:20513682] http://dx.doi.org/10.1176/appi.ps.61.6.589

7. Fear NT, Iversen AC, Chatterjee A, Jones M, Greenberg N, Hull L, Rona RJ, Hotopf M, Wessely S. Risky driving among regular armed forces personnel from the United Kingdom. Am J Prev Med. 2008;35(3):230-36. [PMID:18617356] http://dx.doi.org/10.1016/j.amepre.2008.05.027

8. Kuhn E, Drescher K, Ruzek J, Rosen C. Aggressive and unsafe driving in male veterans receiving residential treatment for PTSD. J Trauma Stress. 2010;23(3):399-402. [PMID:20564373]

9. Lew HL, Kraft K, Pogoda TK, Amick MM, Woods P, Cifu DX. Prevalence and characteristics of driving difficulties in Operation Enduring Freedom/Operation Iraqi Freedom combat returnees. J Rehabil Res Dev. 2011;48(8):913-25. [PMID:22068370] http://dx.doi.org/10.1682/JRRD.2010.08.0140

10. Tefft BC. Asleep at the wheel: The prevalence and impact of drowsy driving. Washington (DC): AAA Foundation for Traffic Safety; 2010.

11. National Highway Traffic Safety Administration. Traffic safety facts 2008. Washington (DC): U.S. Department of Transportation; 2009.

12. National Highway Traffic Safety Administration. An examination of driver distraction as recorded in NHTSA databases. In: Traffic safety facts: Research note: Washington (DC): U.S. Department of Transportation; 2009.

13. Tanielian TL, Jaycox L. Invisible wounds of war: Psychological and cognitive injuries, their consequences, and services to assist recovery. Santa Monica (CA): RAND Center for Military Health Policy Research; 2008.
14. Hoge CW, Castro CA, Messer SC, McGurk D, Cotting DI, Koffman RL. Combat duty in Iraq and Afghanistan, mental health problems, and barriers to care. $\mathrm{N}$ Engl J Med. 2004;351(1):13-22. [PMID:15229303]

15. Vasterling JJ, Proctor SP, Amoroso P, Kane R, Heeren T, White RF. Neuropsychological outcomes of army personnel following deployment to the Iraq war. JAMA. 2006; 296(5):519-29. [PMID:16882958] http://dx.doi.org/10.1001/jama.296.5.519

16. Atkinson MP, Guetz A, Wein LM. A dynamic model for posttraumatic stress disorder among U.S. troops in Operation Iraqi Freedom. Manage Sci. 2009;55(9):1454-68. http://dx.doi.org/10.1287/mnsc.1090.1042

17. Amoroso PJ, Yore MM, Weyandt B, Jones BH. Chapter 8. Total Army injury and health outcomes database: a model comprehensive research database. Mil Med. 1999;164(8 Suppl):1-36. [PMID:10847819]

18. Kraft M, Amick MM, Barth JT, French LM, Lew HL. A review of driving simulator parameters relevant to the Operation Enduring Freedom/Operation Iraqi Freedom veteran population. Am J Phys Med Rehabil. 2010;89(4):336-44. [PMID:20299851] http://dx.doi.org/10.1097/PHM.0b013e3181d3eb5f

19. Clarke DD, Ward P, Bartle C, Truman W. Killer crashes: fatal road traffic accidents in the UK. Accid Anal Prev. 2010; 42(2):764-70. [PMID:20159105] http://dx.doi.org/10.1016/j.aap.2009.11.008

Submitted for publication June 11, 2012. Accepted in revised form September 25, 2012.

This article and any supplementary material should be cited as follows:

Amick MM, Kraft M, McGlinchey R. Driving simulator performance of Veterans from the Iraq and Afghanistan wars. J Rehabil Res Dev. 2013;50(4):463-70. http://dx.doi.org/10.1682/JRRD.2012.06.0108

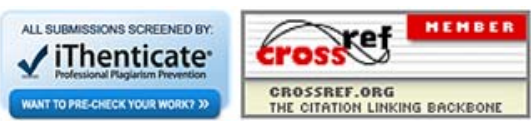

